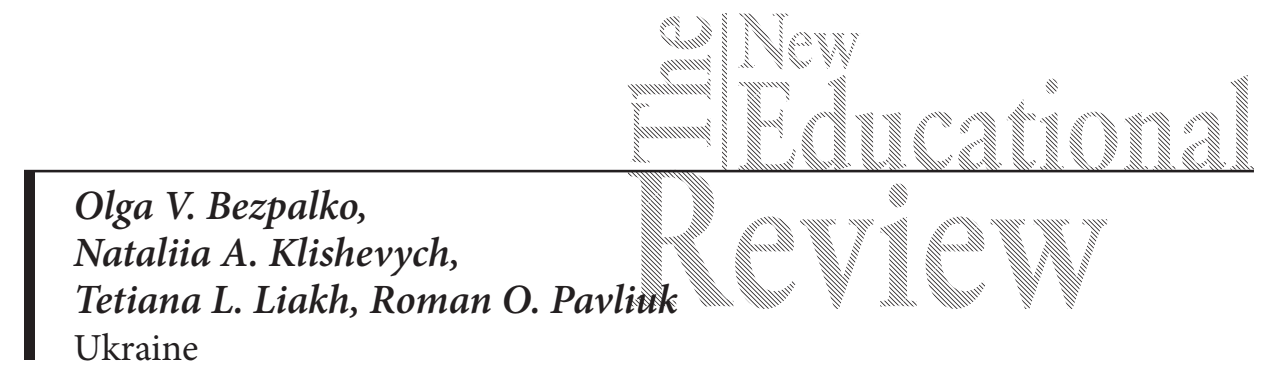

\title{
Criteria and Indicators of University Education Quality: The Results of Expert Interview
}

DOI: 10.15804/tner.2016.46.4.05

\begin{abstract}
The article is devoted to evaluation of criteria and indicators of the measuring of university education quality. On the basis of an expert interview of the teaching/academic staff of the Institute of Human Sciences of Borys Grinchenko Kyiv University, three main criteria were identified (resourses of educational activities, organization of educational activities, the results of specialist training) and their indicators (the level of teaching/academic staff, students as subjects of education, material base, information and methodological support, technologies of training and education, presentation of educational achievements, competitiveness of graduates at the job market, professional achievements of graduates). The proposed criteria and indicators of the quality of education measuring made it possible to evaluate a methodology of measuring/monitoring of university education quality, which is the innovation of our research. A wheel model, whose rung is a criterion indicator, was included in the basis of the methodology of measuring/monitoring of the quality of education. Each rung is also a separate indicator measuring scale and it is divided into ten conditional labels.
\end{abstract}

Keywords: quality of education, criteria and indicators of education quality, measuring of education quality, methodology of measuring/monitoring of education quality 


\section{Introduction}

The issue of education quality is associated with the general competitiveness of the university, its rating, the prestige of graduates, level of the teaching staff, material base, quantitative indicators of students' achievements, the presence of higher educational institutions on the Internet, the number of research projects, etc. The problem of education quality evaluation of both quantitative and qualitative terms arises more and more often today.

But today the is no unified approach to defining the essence of education quality, its indicators and criteria for monitoring, required resources, which are necessary for successful educational activities.

\section{Research Problem Focus}

Foreign researchers investigate education quality as a multidimensional model of evaluation of educational activities that helps to build a conceptually correct system of quality evaluation, determine how development prospects may affect it and provide strategic directions of education quality management (Cheng, Y.C., Tam, W.M., 1997). Other research (Scordoulis, M., et al., 2015) established that education quality can be measured with the use of a set of high-quality components (reputation, academic staff, educational programs, services and additional services, material base) that meet the requirements of students of educational institutions. The level of the teaching/academic staff is an important component of the overall quality of university education. Claudia S. Sarricko \& Andre A. Alves believe that the level of the teaching staff is the key indicator of the quality of education. Here, they include the following: staff qualifications, research capacity/ intensity, individuality, accuracy/punctuality, focus on international cooperation, vocational guidance and inbreeding (Sarricko, C.S, Alves, A.A., 2016).

Other researchers believe that the quality of education can be measured through the system of institutional management and general management (Cardoso, S., Rosa, M.J., Stensaker, B., 2016). The quality of education can also be measured with the use of such indicators as successful lecturer guidance of the teaching process, formation of knowledge, skills and relevant competences, creating a positive attitude to learning and research and creating a favourable educational environment (Ng, P.T., 2015).

Most foreign researchers point out that the quality of education can be measured with the use of two components: indicators/quality measurement criteria that must comply with the specifics of a particular educational institution and be appropriate for clients/applicants of higher education. 
Basically, the quality of education is now measured by ratings of universities, both national and international (Kaidalova, A.V., Posylkina O.N., 2015).

We consider that the quality of education can be measured with the use of a set of competences that determine professional ability to carry out professional activities on a certain level of efficiency with an understanding of social responsibility for its results as the process and the result of the formation of professional competences and professional consciousness of the future specialist.

\section{$\underline{\text { Research Methodology }}$}

At the first stage of the research, we carried out a series of expert interviews with university lecturers. The purpose of the expert interviews was to obtain necessary information reflected in the knowledge, opinions and estimates of the respondents, who are competent persons with experience in the monitoring of educational quality. The possibility of participation was limited to the teaching staff of the Institute of Human Sciences. It is a structural subdivision of Borys Grinchenko Kyiv University (Ukraine) and has five departments: anatomy and physiology; general, age and pedagogical psychology; practical psychology; special psychology, correctional and inclusive education; social pedagogy and social work.

The respondents were invited to participate in the interviews through announcements posted on the website of the Institute of Human Sciences and personal letters to lecturers and heads of departments.

The grounded theory, presented in the studies of Kathy Charmez (Charmaz, K., 2014), was the basis for data collection and for the theoretical part of the study. The initial set of respondents was intended to secure a sample of teachers who have different views on the necessity of monitoring of education quality and vary in age, academic degree and position. This stage of the research interviews was based on open questions and topics concerning how the teachers monitor the quality of education.

According to the methodology of grounded theory, encoding occurred simultaneously with data collection. Initial encoding was open and close to the text, this means that the codes were designed to reflect the actions, intentions and meanings of the respondents, often using their own words. Further interview encoding was the current use of comparative analysis that made it possible to identify such codes into categories.

After initial isolation of the categories, it modified the process of attracting participants. To provide the most diverse selection, participants were selected 
according to their ability to explain the specific issues which had been identified in the previous study. This approach is called "theoretical sampling" (Glaser, B.G., Strauss, A.L., 2012) and it allows for formulating specific questions for interviews. The list of previously investigated topics of semi-structured interviews include: indicators of the criteria of education quality, "the level of teaching/academic staff", "students as subjects of education" "material base", "information and methodological support", "technologies of training and education", "presentation of educational achievements", "competitiveness of graduates on the job market", "professional achievements of graduates". Data collection continued in the same direction until the answer to the question in the current study was answered and an appropriate model was fully developed.

At this stage, the application of analysis together with data collection was continued. Encoding was re-formatted from open to theoretical encoding, which allowed for drawing parallels between the codes and categories, categories and indicators with further order to search definitions. Notes, including the development of models, were used to conduct comparisons. Such a methodology led to the evaluation of the theoretical model of monitoring of the quality of education.

In order to assess the validity of the final results, five teachers (one from each department) who had taken part in interviews were invited to analyse the model and comment on it. The lecturers differed in decision making for the organization of monitoring of educational quality but they generally were matching the sampling. After that another five lecturers who had not taken part in the study (including one from each department) were invited to review and provide comments. The responses were carefully analyzed and some minor changes were made.

\section{Research Results}

Expert interviews were held with 55 teachers of the Institute of Human Sciences. The interview began with questions about personal data.

Findings of this survey allowed for formulating 3 criteria groups of the quality of education and accordant indicators, which are presented Figure 1.

The respondents suggested the following four indicators in the first criterion, resources of the educational process: the level of the teaching/academic staff, students as subjects of education, material base, information and methodological support. They were asked to identify the contents of each indicator and specify the tasks to improve its effectiveness. 
Table 1. Information about the respondents

\begin{tabular}{|c|c|}
\hline Age range & $23-64$ \\
\hline \multirow[t]{2}{*}{ Gender (\%) } & Male $-4(7.3 \%)$ \\
\hline & Female - $51(92.7 \%)$ \\
\hline \multirow[t]{5}{*}{ Position (\%) } & Assistant - $2(3.6 \%)$ \\
\hline & Lecturer - $7(12.7 \%)$ \\
\hline & Senior Lecturer - $13(23.6 \%)$ \\
\hline & Assistant Professor - 27 (49\%) \\
\hline & Professor - $6(11.1 \%)$ \\
\hline \multirow[t]{3}{*}{ Education, scientific degree (\%) } & Higher education - $55(100 \%)$ \\
\hline & $\mathrm{PhD}-38(69 \%)$ \\
\hline & Doctor of sciences - 5(31\%) \\
\hline
\end{tabular}

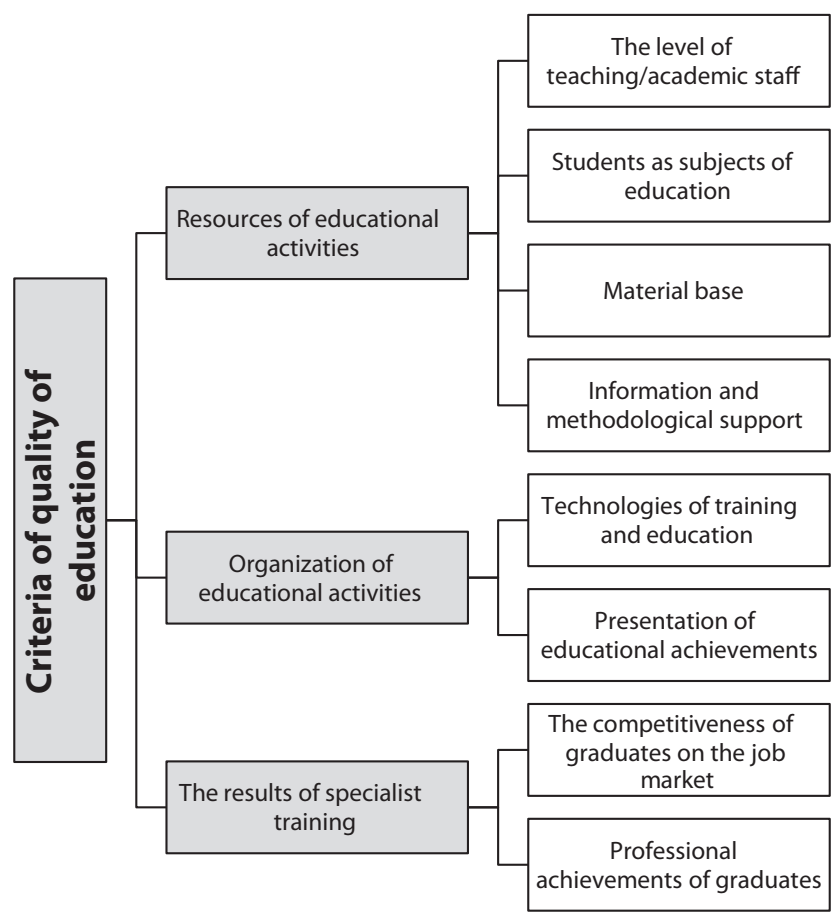

Figure 1. Criteria groups of quality of education and accordant indicators 
The first indicator is the level of the teaching/academic staff. To ensure its quality, according to the respondents, it is implemented: "there is a procedure for measuring of ratings of the teaching/academic staff of the University" as guarantors of the quality of education; "there is the system of updating of electronic portfolio"; "all research/publications of the teaching/academic staff are posted in the university repository"; "internship opportunities based on national and international organizations" is provided with the aim to increase the level of knowledge and innovative technologies of teaching/academic staff. The respondents stated that the objectives of strengthening and capacity building of the teaching staff are "improving the procedure of ratings of teaching/academic staff with transparency and accessibility to public discussion", "motivation of teachers to professional growth and self-improvement", "cooperation with leading scientists from foreign countries, international organizations, funds for participation in international research projects", then it needs to provide opportunities for communication through "providing of English courses", "providing methodological seminars and training for the teaching/academic staff according to their professional requests and needs".

Another indicator is the students as subjects of educational activities. This indicator was the most controversial. The respondents insisted on the importance of "formation of students' personal responsibility for the quality of education". They emphasized the "distribution of responsibility between all participants in the educational process", insisting that "the teacher competence requirements are greater every year, and students remain almost constant". This leads to the fact that the teacher is responsible for the student's academic failure. The educational process at the Institute of Human Sciences provides "a survey of students to determine their moral attitudes in obtaining education". Also, the respondents paid attention to the need for "monitoring of the influence of the philosophy of leadership-serving on personal and professional development of students" because Borys Grinchenko Kyiv University professing leadership as serving as one of the key values of the institution.

Another important aspect of this indicator is "the development of social activity of students through attraction to volunteering and charity". The respondents noted that the students of the Institute can "not only take part in charitable projects and volunteer initiatives, but produce their own charitable and volunteer projects", "create charity foundations and public organizations".

The respondents also focused on the problem areas centered on the conditions of students' subjectivity: "providing social and psychological support to students at the "teacher-student", "student-student" levels, which can be realized through the "functioning of student social and psychological services"; «arranging the 
meetings of students with graduates of the Institute whose life success stories would inspire to study"; "evaluation of social activity of students by initiating and participating in projects at the university, local, national and international levels".

Material base was the third indicator of "resources of the educational process". The respondents noted that the Institute of Human Sciences established "systematic replenishment of resourse centre with modern teaching materials", «new remote format of work (making online orders, informing about new items), we believe that this is a highlight of our institution", «new classes for students: practical "Logo-simulator" training centre, diagnostic and consultative centre of practical psychology, art studio». However, they unanimously consider that we should work towards strengthening the material base: "we need to purchase software and methodological support for the "Logo-simulator" centre, diagnostic and consultative centre of practical psychology, art studio that will significantly improve the practical training component of students", «we widely use interactive learning, and our classes do not allow for full use of the space for interactive learning limiting opportunities to work in groups. Therefore, it is imperative to pay attention to arrangement of classrooms with modified furniture", "importance of creation of platforms for the workshops based in educational and social institutions. This is beneficial not only to employers and universities. First of all, this would benefit students in receiving invaluable practical experience in conditions close to real». The respondents agreed on the need for "evaluation and implementation of fundraising programs for the material support of new disciplines (Coaching Studies, School of professional skills, workshops, etc.)".

And the last indicator for the above criterion is information and methodological support. The respondents noted that the Institute is conducting now "an annual analysis and updating of training and methodological support of the departments", "presentation of information-training and methodological support on e-pages of the departments", "the usage of certified e-learning courses in the educational process of full-time and correspondence forms of studying". But they pointed out the necessity to focus on the following aspects: «supplementing of the contents of modules of subjects, themes with the latest research, trends in professional activities, socio-cultural situation demands of employers and students, etc.", "correlation of practice tasks with the disciplines of the educational program (to avoid situations such as education separately - practice separately)", "according to the research-based training concept to allow the student to determine the problem of master's thesis", "the usage of social networks as a resource for professional self-development of students and lecturers". 
For the second criterion - organization of educational activities - the respondents suggested two indicators: technologies of training and education, presentation of educational achievements. According to the respondents, the Institute provides: «forming of professional competence on visiting classes to various organizations, institutions and services»" "presenting different training courses as part of additional educational services aimed at formation of special professional competence", "usage of interactive learning during lectures, giving practical exercises, examples from real life, the media, etc.", «usage of the results of modern scientific research, materials from abstracts of dissertations, scientific publications of lectures and seminars", "continuous practice of students "from volunteering - to internship" at various educational institutions and social services (for minors in "Social Pedagogy", "Special Education (speech therapy)", "Social Work")". They noted that all this "will enable further employment of graduates of the Institute". There were proposals in the respondents' answers about transition to the new educational quality. They include «conducting guest lectures by leading national and foreign scientists and practitioners», «attracting potential employers to conducting lectures and practical training, extracurricular forms of work», «reorientation of forms of control of students' academic achievements in core subjects into presenting of their projects, technologies, methods, etc.», "expert survey of organizations' specialists who are supporting students during training with the aim of monitoring the process of practical training".

In order to ensure the "presentation of educational achievements" indicator, according to the respondents what should be done is "constant updating of e-pages of departments and website of the Institute with innovation, scientific and educational achievements of students and teaching/academic staff, etc.", "popularizing in social networks of professional oriented, practical activities of the Institute, departments in different directions". What was emphasized was "create students' V-Blog (YouTube video channel of Students' Parliament of the Institute of Human Sciences)".

However, the respondents noted that the change and expansion of the popularization of the University and the Institute may be due to "creation of personal sites, pages of lecturers, scientific schools, scientific clubs", "further presentation of students' academic achievements through their own electronic journal of scientific papers "Scientific achievements of students of the Institute of Human Sciences", "presentation by students and teachers of the results of their research activities in educational institutions and social services departments".

The third criterion - results of theeducational process - includes two indicators: the competitiveness of graduates on the job market, and professional achievements of graduates. 
The respondents noted that during investigation of the first indicator - competitiveness of graduates on the labour market - we should "explore opportunities for employment of graduates in various institutions of social and educational sphere of Kyiv, as Grinchenko University is a municipal institution" "systematically investigate the social needs and requests of the Kyiv community on the need for corresponding specialists", "promote potential of graduates at various levels and by various means, including through social networks" "monitor current requests of agencies of the social and educational sphere in order to constantly update the variable part of educational programs and systematic catalogue supplement with additional educational services", "enhance professional cooperation with potential employers".

The second indicator - professional achievement of graduates - is provided, according to the respondents, through the "involvement of graduates in scientific research activities within departments", "creating an interactive platform for communication, advocacy of professional interests of graduates of the Institute", "coverage of professional achievements of graduates in social and professional networks, Institute web-site".

\section{Discussion and Conclusions}

All the respondents pointed out the importance of elaboration of "an easy to use methodology of monitoring the quality of education". The proposed criteria and indicators of education quality measurement made it possible to evaluate a methodology of measuring/monitoring of education quality.

A wheel model (Figure 2), whose rung is a criterion indicator, was included in the basis of the methodology of measuring/monitoring of the quality of education. Those indicators were investigated and evaluated through the expert interview of the teaching and academic staff of the Institute of Human Sciences of Borys Grinchenko Kyiv University. Each rung is also a separate indicator measuring scale. It is divided into ten conditional labels. Evaluation can be made individually or by a group (e.g., by members of the department, by the management of the Institute).

Measuring of achievements for each indicator is determined by choosing a certain point on the scale of rungs. The nearer the mark is to the center of the circle, the lower the achievement on this indicator. The further the mark is from the center, the better the results are on the defined indicator. Indications must be connected by a smooth line clockwise. This visualization enables participants 


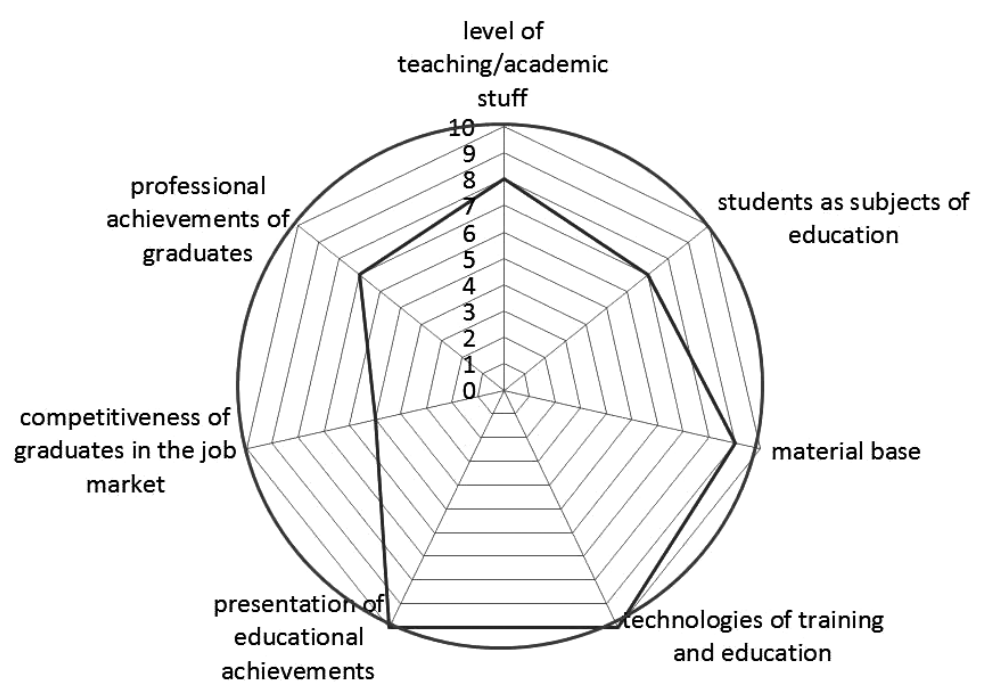

Figure 2. Visualization of monitoring of the quality of education in higher education institutions

to analyse the education quality assurance, achievements and failures of each indicator, to identify the ways of improving the quality of education.

The results of the study were presented at the methodological seminar for the teaching and academic staff of the Institute of Human Sciences. The teaching and academic staff were invited to discuss the methodology for monitoring of the quality of education. The participants noted that «the methodology allows for filling the proposed criteria, investing into them modern content", "the scheme for monitoring of education quality is easy to use and can be used for individual teacher self-diagnosis and for a department, institution".

The findings of this study have some limitations. First, qualitative research cannot be generalized. It means that the results of this study are not representative for other institutions of Borys Grinchenko Kyiv University, universities of Ukraine. Secondly, the study was limited only to experts of teaching and academic staff of the Institute of Human Sciences of Borys Grinchenko Kyiv University. Thus, the experience of teaching and academic staff of other universities is not presented in this study. 
Finally, this study allows for understanding that approaches to monitoring of the quality of education should be based on how teachers evaluate the quality of education, along with other important factors such as the resources, process, and results of the educational process.

Acknowledgements: The research was done within the evaluation of scientific theme of the Institute of Human Sciences "Personality in terms of social transformations of modern Ukraine", registration number 0116U002960, term of implementation - 5.2016-5.2021.

\section{References}

Cardoso, S., Rosa, M.J., Stensaker, B. (2016). Why is quality in higher education not achieved? The view of academics. Assessment \& evaluation in higher education, 41, Iss.6, 950-965. doi.org/10.1080/02602938.2015.1052775.

Charmaz, K. (2014). Constructing grounded theory. $2^{\text {nd }}$ edition. Dorchester. The Dorset Press.

Kaidalova, A.V., Posylkina O.N. (2015). Theoretical and methodological approaches to measuring of quality of education in the context of higher educational establishments rating. Pharmaceutic Bulletin, 4, 75-81. doi: 10.11603/2312-0967.2015.4.5562.

Ng, P.T. (2015) What is quality education? How can it be achieved? The perspectives of school middle leaders in Singapore. Educational Assessment, Evaluation and Accountability, 27, Iss.4, 307-322. doi:10.1007/s11092-015-9223-8.

Sarrico, C.S., Alves, A.A. (2016). Academic staff quality in higher education: an empirical analysis of Portuguese public administration education. Higher education, 71, Iss.2, 143-162. doi:10.1007/s10734-015-9893-7.

Scordoulis, M., Sparanglis, P., Stampolis, O., Mougkolia, I., Papageorgiou, A., Chondreli., C. (2015) A framework for quality in education: applying quality function deployment a higher educational institute. International Scientific Conference "e-RA - 10".

Sukhova, N.M. (2005). Quality of higher education as one of philosophical basis of transforming of the education in the XXI century: European aspect, available online at: http://www.nbuv.gov.ua/old_jrn/soc_gum/Vnau_f/2009_1/suxov.pdf.

Teeroovengadum, V., Kamalanabham, T.J., Seebaluck, A.K. (2016). Measuring service quality in higher education. Quality Assurance in Education, 24, Iss.2, 244-258. doi: 10.1108/ QAE-06-2014-0028.

Yin Cheong Cheng, Wai Ming Tam, (1997). Multi-models of quality in education. Quality assurance in education. 5 Iss:1, 22-31.

Glaser, B.G. \& Strauss, A.L. (2012). The Discovery of Grounded Theory: Strategies for Qualitative Research. New Brunswick \& London. Aldine Transaction. 